\title{
Evaluation of the stability of Polymyxin B in saline and glucose solutions using LC-MS/MS
}

\author{
Juliana Kich Castilhos', Thaís Luise Dillenburg¹, Marina Venzon Antunes², Letícia Scribel ${ }^{\circledR 3}$, \\ Alexandre Prehn Zavascki ${ }^{\oplus 4}$, Rafael Linden², Simone Gasparin Verza ${ }^{\circledR *}$
}

\begin{abstract}
${ }^{1}$ Bioanalysis Laboratory, Institute of Health Sciences, Feevale University, Novo Hamburgo-RS, Brazil, ${ }^{2}$ Toxicological Analysis Laboratory, Institute of Health Sciences, Feevale University, Novo Hamburgo-RS, Brazil, ${ }^{3}$ Federal Institute of Education, Science and Technology of Rio Grande do Sul - Campus Porto Alegre, Brazil, ${ }^{4}$ Department of Internal Medicine, Federal University of Rio Grande do Sul, Porto Alegre, Brazil
\end{abstract}

\begin{abstract}
Polymyxins are a group of antibacterial substances and have remained the drugs of choice for treatment of resistant Gram-negative bacilli. Polymyxin B is administered by intravenous infusion and requires the reconstitution of lyophilized powder with $0.9 \%$ saline or $5 \%$ glucose solutions. To date, there is little information about polymyxin stability in different infusions solutions, especially at $40{ }^{\circ} \mathrm{C}$, a temperature that is recommended to study drug stability as it accelerates degradation reactions. Therefore, in this work an analytical method using LC-MS/MS was developed, validated and applied to determine the stability of polymyxin B diluted in $0.9 \%$ saline or $5 \%$ glucose solutions at $25^{\circ} \mathrm{C}$ and $40{ }^{\circ} \mathrm{C}$. The stability of polymyxin B solutions was evaluated during 72 hours. Polymyxin B1 and B2 were stable for 24 hours in saline $(0.9 \%)$ and glucose solution $(5 \%)$, however a significant degradation of polymyxin B1 and B2 was observed after 48 hours and 72 hours of assay. The reduction of polymyxin content was evidenced in both saline and glucose media, at room temperature as well as at $40{ }^{\circ} \mathrm{C}$. No significant differences in $\mathrm{pH}$ of polymyxin solutions (glucose or saline) were evidenced during stability assay.
\end{abstract}

Keywords: Polymyxin. Stability. LC-MS/MS. Glucose solutions. Saline solutions.

\section{INTRODUCTION}

Polymyxins are a group of antibacterial substances developed for clinical use in 1947. Released in the late 1950 s, they remained largely unexplored due to their toxicity and the availability of other more tolerable groups of antibiotics including $\beta$-lactams and aminoglycosides (Zavascki et al., 2007). However, polymyxins has reemerged in clinical practice in the last 15 years owing to the worldwide dissemination of extensively-drugresistant Gram-negative infections, notably, Psedomonas aeruginosa, Acinetobacter baumannii and Klebsiella pneumonia (Pogue, Ortwine, Kaye, 2017).

Polymyxin B, a member of the class of polymyxins, consists mainly of a mixture of polymyxins B1 and B2, which are usually derived from Bacillus polymyxa and administered as sulfate salts (USP, 2015). The polymyxin B package insert indicates that the intravenous administration

\footnotetext{
*Correspondence: S. G. Verza. Instituto de Ciências da Saúde, Universidade Feevale, ERS 239, n 2755, Novo Hamburgo, RS, Brazil, Postal code 93525-075. Phone: +55 513586 8800. E-mail: simonev@feevale.br
}

of polymyxin $B$ requires the reconstitution of the lyophilized powder $(500,000 \mathrm{IU})$ with sterile water for injection and the infusion of this mixture must be made in 300 to 500 $\mathrm{mL}$ solutions of either $0.9 \%$ saline or $5 \%$ glucose (Trissel, 2012). However, such a volume may be excessively high for some critically ill patients who have either risk of developing fluid overload states or have restriction of fluid infusion due to several conditions. Therefore, stability of polymyxin B in lower volume solutions is of paramount importance and for which the administration should be performed slowly (Lim et al., 2016).

Previous studies reported stability of polymyxins $\mathrm{B} 1, \mathrm{E} 1$ and $\mathrm{E} 2$ subjected to different $\mathrm{pH}$ values and temperatures (Orwa et al., 2002). The stability of polymyxin B was evaluated also in $0.9 \%$ saline solutions stored at room temperature and under refrigeration using a microbiological assay (He et al., 2010). In a more recent study the stability of polymyxin $\mathrm{B}$ was evaluated in various reduced infusion volumes of $0.045 \%, 0.225 \%$ and $0.9 \%$ saline, and $5 \%$ dextrose stored at 4,25 and $30{ }^{\circ} \mathrm{C}$ (Lim et al., 2016). 
Nonetheless, stability studies of polymyxin B in $0.9 \%$ saline and $5 \%$ glucose solutions at room temperature and $40{ }^{\circ} \mathrm{C}$ is unavailable in scientific literature, especially using high-performance analytical methods such as LC-MS/MS. Therefore, the objective of this study was to evaluate the stability of polymyxins B1 and B2 in $0.9 \%$ saline and $5 \%$ glucose infusion solutions, at room temperature and at $40{ }^{\circ} \mathrm{C}$ for 72 hours. It is worth noting the recommendation of the temperature of $40{ }^{\circ} \mathrm{C}$ to study drug stability, as it accelerates degradation reactions providing indication of long-term stability (ICH 2003; WHO 2009). For drug quantification, we employed an LC-MS/MS methodology previously developed and validated.

\section{MATERIAL AND METHODS}

\section{Standard, samples and other materials}

The reference substance of polymyxin B sulfate (batch \#BCBF 8382V) was purchased from Sigma-

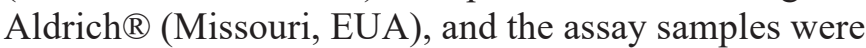
purchased from Eurofarma ${ }^{\circledR}$ (Brazil). Saline solutions $(0.9 \%)$ and $5 \%$ glucose solutions (Baxter ${ }^{\circledR}$, Brazil), as well as sterile water for injection (Isofarma ${ }^{\circledR}$, Brazil) were also purchased. The analyses were performed using $0.1 \%$ formic acid (Merck ${ }^{\circledR}$, Germany), methanol (Merck ${ }^{\circledR}$, Germany) and purified water obtained using a Milli- ${ }^{\circledR}$ system (Merck Millipore Corporation ${ }^{\circledR}$, France). For solvent filtration, a $0.22 \mu \mathrm{m}$ Sartorius Stedim Biotech (Germany) membrane was used.

\section{Equipment and analytical conditions}

The quantification of polymyxin B was performed on a liquid chromatograph with mass detector (LC-MS/MS) from Thermo Scientific ${ }^{\mathrm{TM}}$ (United States), model UltiMate ${ }^{\mathrm{TM}} 3000$ with RS column housing, XRS autosampler, and XRS pump all from Thermo Scientific. The software Thermo Xcalibur Roadmap was used for data management.

During the analyses, an ACE 3 C18 column $(50 \mathrm{~mm} \times 2.1 \mathrm{~mm} \mathrm{id} ; 3 \mu \mathrm{m})$ was used, conditioned at a temperature of $30^{\circ} \mathrm{C}$. The mobile phase consisted of $0.1 \%$ formic acid (A) and methanol (B) at flow rate of $0.3 \mathrm{~mL} / \mathrm{min}$ in linear gradient system: 0 to $5.0 \mathrm{~min}, 10$ to $18 \% \mathrm{~B} ; 5.0$ to $5.5 \mathrm{~min}, 18 \% \mathrm{~B}$; 5.5 to $7.5 \mathrm{~min}, 18$ to $95 \% \mathrm{~B}$; 7.5 to $8.0 \mathrm{~min}, 95 \% \mathrm{~B}$; and 8.0 to $11.0 \mathrm{~min}, 95$ to $10 \% \mathrm{~B}$. The volume of sample injection was $10 \mu \mathrm{L}$.

Detection was performed using positive mode electrospray ionization, and the predominant ions produced were $[\mathrm{M}+2]^{2+}$ monitoring $\mathrm{m} / \mathrm{z}$ transitions 602.5 for polymyxin B1 and 595.5 for polymyxin B2. The parameters optimized to carry out the analyzes were capillary voltage of $5.0 \mathrm{kV}$, capillary temperature of $200{ }^{\circ} \mathrm{C}$, vaporizer temperature of $432^{\circ} \mathrm{C}$, cone gas flow of $15 \mathrm{Arb}$ and nitrogen nebulizer gas flow of $50 \mathrm{Arb}$.

\section{Validation of the analytical method}

The analytical method was validated considering specificity, linearity, accuracy, precision (ICH, 2005) and the suitability of the analytical method was assured.

The specificity of the analytical method was evaluated by injecting $0.9 \%$ saline and $5 \%$ glucose solutions under the analytical conditions described above. Linearity was assessed based on three analytical curves prepared on three consecutive days in the concentration range of 5 to $30 \mu \mathrm{g} / \mathrm{mL}$. For this purpose, a $5 \mathrm{mg}$ polymyxin standard solution was prepared $10 \mathrm{~mL}$ in a volumetric flask using acetonitrile in water $(20: 80 \mathrm{v} / \mathrm{v})\left(\right.$ LiChrosolv $^{\circledR}$, Germany). From this solution, further dilutions were made using a solution of $0.1 \%$ formic acid and methanol (80:20 $\mathrm{v} / \mathrm{v}$ ), comprising the concentration range aforementioned. The limits of detection (LOD) and quantification (LOQ) were calculated from the analytical curve (ICH, 2005). Accuracy was determined by recovery assay. For that purpose, solutions of $7.5 \mu \mathrm{g} / \mathrm{mL}, 17.5 \mu \mathrm{g} / \mathrm{mL}$ and $27.5 \mu \mathrm{g} / \mathrm{mL}$ polymyxin were prepared in $0.9 \%$ saline and $5 \%$ glucose solutions. The content recovered was calculated in percentage. Intra-assay precision was evaluated by 9 analyses of the mean point of the analytical curve $(20 \mu \mathrm{g} / \mathrm{mL})$ and the inter-day precision by means of the analysis of the results obtained at low, medium and high concentrations obtained for three different analytical curves prepared on three consecutive days. Both results were expressed as relative standard deviation (RSD\%) (ICH, 2005).

\section{Stability analysis}

Polymyxin B samples submitted to the stability assay were individually prepared by diluting one ampoule of polymyxin B (500,000 IU), which is equivalent to $50 \mathrm{mg}$, in $2 \mathrm{~mL}$ of sterile water for injection. Subsequently these samples were injected into $500 \mathrm{~mL}$ infusion bags containing $0.9 \%$ saline or $500 \mathrm{~mL}$ infusion bags containing $5 \%$ glucose, and maintained at room temperature $\left(25^{\circ} \mathrm{C}\right)$ or in a heating oven at $40{ }^{\circ} \mathrm{C}\left(\mathrm{De}\right.$ Leo ${ }^{\circledR}, \mathrm{DU} 215 \mathrm{CD}$, Brazil). All samples were obtained in triplicates.

For the LC-MS/MS analyses, all samples were diluted to $20 \mu \mathrm{g} / \mathrm{mL}$ with $0.1 \%$ formic acid in methanol 
$(80: 20 \mathrm{v} / \mathrm{v})$. The analyses were performed at the assay times of $0,4,8,24,48$ and 72 hours and the percentage of polymyxin $\mathrm{B} 1$ and $\mathrm{B} 2$ was expressed. The $\mathrm{pH}$ of saline and glucose solutions of polymyxin B1 and B2 was measured at the same time interval mentioned above.

\section{Statistical analysis}

The influence of time and temperature on the stability of polymyxins B1 was analyzed by one-way analysis of variance (ANOVA), and subsequently, by a Tukey test using SPSS version 22 for windows. A value of $\mathrm{P}<0.05$ was considered statistically significant.

\section{RESULTS AND DISCUSSION}

\section{LC-MS/MS analyses}

The analytical method was proposed based on the chromatographic conditions described previously
(Thomas et al., 2012) with modifications. In the analytical conditions presented here, there was co-elution of the polymyxin B1 and B2 signals around 7.7-7.9 min. The detection was not influenced by the co-elution since it was performed monitoring $\mathrm{m} / \mathrm{z}$ transitions: $\mathrm{m} / \mathrm{z}$ $593.7 \rightarrow \mathrm{m} / \mathrm{z} 482.20$ and $\mathrm{m} / \mathrm{z} 586.7 \rightarrow \mathrm{m} / \mathrm{z} 101.00$ for polymyxin B1 and B2, respectively (Figure 1).

The quantification of polymyxin B1 and B2 was satisfactory based on the validation parameters (Table I). The calibration curves of polymyxin B1 and B2 were found to be linear, both with correlation coefficients $\left(\mathrm{r}^{2}\right)>0.994$ in the concentration range of $5.0-30 \mu \mathrm{g} / \mathrm{mL}$. The intra-day and inter-day precision tests were considered satisfactory with coefficients of variation (RSD) lower than $2.93 \%$ and $4.08 \%$, respectively. The method's accuracy was within range of $96.1 \%$ to $104.1 \%$ for polymyxin B1 and $97.9 \%$ to $103.0 \%$ for polymyxin $\mathrm{B} 2$.

Analyzing the results obtained during the stability tests, polymyxin B1 and B2 were stable for 24 hours when it was diluted in saline $(0.9 \%)$ and glucose solution $(5 \%)$.
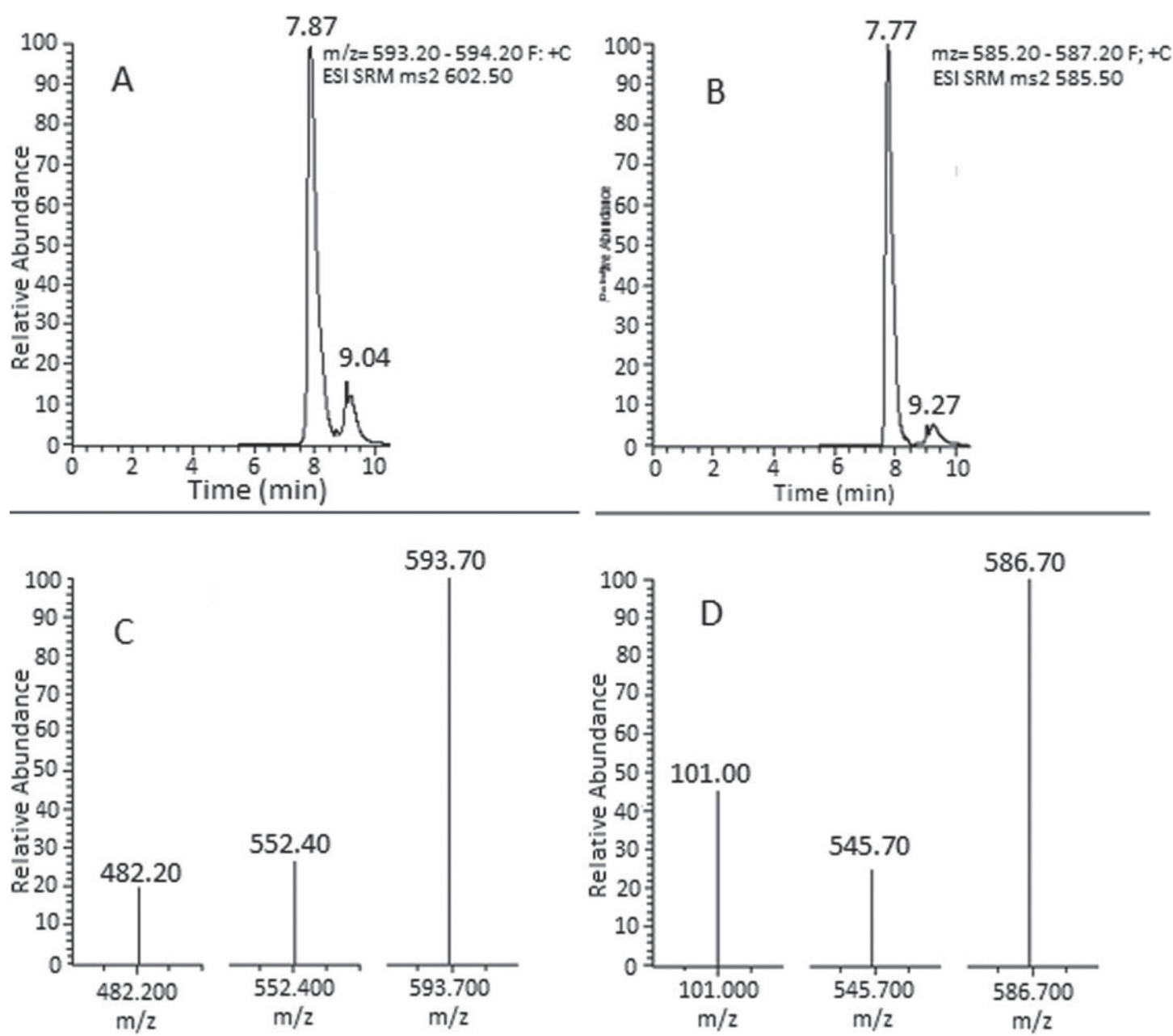

FIGURE 1 - Chromatograms of standard solutions: Polymyxin B1 (A) and Polymyxin B2 (B). Mass transitions from Polymyxin B1 (C) and Polymyxin B2 (D). 
TABLE I - Results of analytical method validation

\begin{tabular}{|c|c|c|c|}
\hline \multirow{2}{*}{\multicolumn{2}{|c|}{ Validation parameter }} & \multicolumn{2}{|c|}{ Results } \\
\hline & & Polymyxin B1 & Polymyxin B2 \\
\hline \multicolumn{2}{|c|}{ Equation } & $\mathrm{y}=4931352 \mathrm{x}-1,9 \mathrm{E}+07$ & $\mathrm{y}=3450874 \mathrm{x}-1,1 \mathrm{E}+07$ \\
\hline \multicolumn{2}{|c|}{$\mathrm{r}^{2}$} & 0.9960 & 0.9948 \\
\hline \multicolumn{2}{|c|}{$\operatorname{LOD}^{\mathrm{a}}(\mu \mathrm{g} / \mathrm{mL})$} & 0.183 & 0.209 \\
\hline \multicolumn{2}{|c|}{$\mathrm{LOQ}^{\mathrm{b}}(\mu \mathrm{g} / \mathrm{mL})$} & 1.611 & 1.699 \\
\hline \multicolumn{2}{|c|}{ Intra-day precision $\left(\mathrm{RSD}^{\mathrm{c}} \%\right)(\mathrm{n}=9)$} & $\leq 2.42 \%$ & $\leq 2.93 \%$ \\
\hline \multicolumn{2}{|c|}{ Inter-day precision $\left(\mathrm{RSD}^{\mathrm{c}} \%\right)(\mathrm{n}=9)$} & $\leq 4.08 \%$ & $\leq 3.96 \%$ \\
\hline \multicolumn{4}{|c|}{ Accuracy } \\
\hline \multirow{3}{*}{$5 \%$ Glucose } & $7.5 \mu \mathrm{g} / \mathrm{mL}$ & $99.20 \%( \pm 0.02)$ & $102.61( \pm 1.96)$ \\
\hline & $17.5 \mu \mathrm{g} / \mathrm{mL}$ & $97.67 \%( \pm 3.33)$ & $98.37( \pm 3.59)$ \\
\hline & $27.5 \mu \mathrm{g} / \mathrm{mL}$ & $104.08 \%( \pm 2.87)$ & $100.72( \pm 1.93)$ \\
\hline \multirow{3}{*}{$0,9 \%$ Saline } & $7.5 \mu \mathrm{g} / \mathrm{mL}$ & $102.77 \%( \pm 2.80)$ & $103.01( \pm 0.94)$ \\
\hline & $17.5 \mu \mathrm{g} / \mathrm{mL}$ & $96.09 \%( \pm 1.62)$ & $102.77( \pm 2.65)$ \\
\hline & $27.5 \mu \mathrm{g} / \mathrm{mL}$ & $97.39 \%( \pm 3.09)$ & $97.88( \pm 2.71)$ \\
\hline
\end{tabular}

${ }^{\mathrm{a}} \mathrm{LOD}$, limit of detection; ${ }^{\mathrm{b}} \mathrm{LOQ}$, limit of quantification ; ${ }^{\mathrm{RSD}} \%$, relative standard deviation

TABLE II - Percentage of Polymyxin B1 and B2 during the stability assay

\begin{tabular}{lccccccc}
\hline \multicolumn{7}{c}{ Polymyxin B1 } \\
\hline Diluent & Temperature & $\mathbf{0}$ & $\mathbf{4}$ hours & $\mathbf{8}$ hours & $\mathbf{2 4}$ hours & $\mathbf{4 8}$ hours & $\mathbf{7 2 ~ h o u r s}$ \\
\hline \multirow{2}{*}{$0.9 \%$ Saline } & Room temperature & $100^{\mathrm{a}}$ & $99.0^{\mathrm{a}} \pm 2.2$ & $101.2^{\mathrm{a}} \pm 4.8$ & $96.8^{\mathrm{a}} \pm 1.7$ & $73.9^{\mathrm{b}} \pm 6.7$ & $81.2^{\mathrm{b}} \pm 4.0$ \\
& $40^{\circ} \mathrm{C}$ & $100^{\mathrm{a}}$ & $100.8^{\mathrm{a}} \pm 3.3$ & $100.7^{\mathrm{a}} \pm 3.0$ & $98.1^{\mathrm{a}} \pm 1.6$ & $81.9^{\mathrm{b}} \pm 4.2$ & $86.6^{\mathrm{b}} \pm 0.9$ \\
\hline \multirow{2}{*}{$5 \%$ Glucose } & Room temperature & $100^{\mathrm{a}}$ & $104.8^{\mathrm{a}} \pm 3.4$ & $96.9^{\mathrm{a}} \pm 4.9$ & $93.5^{\mathrm{a}} \pm 2.0$ & $73.3^{\mathrm{b}} \pm 5.1$ & $79.1^{\mathrm{b}} \pm 2.5^{\mathrm{a}}$ \\
& $40^{\circ} \mathrm{C}$ & $100^{\mathrm{a}}$ & $104.3^{\mathrm{a}} \pm 7.1$ & $100.8^{\mathrm{a}} \pm 2.9$ & $86.3^{\mathrm{b}} \pm 1.9$ & $81.7^{\mathrm{b}} \pm 4.0$ & $83.3^{\mathrm{b}} \pm 2.4$ \\
\hline \multicolumn{7}{c}{ Polymyxin $\mathbf{B 2}$} \\
\hline Diluent & Temperature & $\mathbf{0}$ & $\mathbf{4}$ hours & $\mathbf{8}$ hours & $\mathbf{2 4}$ hours & $\mathbf{4 8}$ hours & $\mathbf{7 2}$ hours \\
\hline \multirow{2}{*}{$0.9 \%$ Saline } & Room temperature & $100^{\mathrm{a}}$ & $98.9^{\mathrm{a}} \pm 3.4$ & $100.4^{\mathrm{a}} \pm 4.0$ & $92.5^{\mathrm{a}} \pm 1.2$ & $80.2^{\mathrm{b}} \pm 3.6$ & $87.1^{\mathrm{b}} \pm 4.4$ \\
& $40^{\circ} \mathrm{C}$ & $100^{\mathrm{a}}$ & $100.8^{\mathrm{a}} \pm 3.6$ & $100.6^{\mathrm{a}} \pm 2.2$ & $103.3^{\mathrm{a}} \pm 1.6$ & $88.4^{\mathrm{b}} \pm 5.1$ & $87.8^{\mathrm{b}} \pm 3.0$ \\
\hline \multirow{2}{*}{ 5\% Glucose } & Room temperature & $100^{\mathrm{a}}$ & $102.9^{\mathrm{a}} \pm 6.8$ & $95.8^{\mathrm{a}} \pm 3.6$ & $93.2^{\mathrm{a}} \pm 2.9$ & $82.0^{\mathrm{b}} \pm 4.7$ & $85.7^{\mathrm{b}} \pm 5.6$ \\
& $40^{\circ} \mathrm{C}$ & $100^{\mathrm{a}}$ & $106.9^{\mathrm{a}} \pm 5.4$ & $100.4^{\mathrm{a}} \pm 3.9$ & $90.7^{\mathrm{a}} \pm 2.3$ & $90.7^{\mathrm{b}} \pm 4.2$ & $86.9^{\mathrm{b}} \pm 1.1$ \\
\hline
\end{tabular}

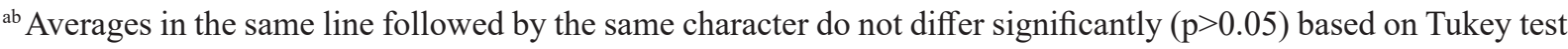

For all samples, a reduction of polymyxin B concentration greater than 5\% was observed after 24 hours. Meantime, no significant difference between the contents of polymyxin $\mathrm{B} 1$ and $\mathrm{B} 2$ during the first $24 \mathrm{~h}$ was evidenced.

In order to verify the influence of temperature and time at stability of polymyxin B1 and B2 one-way analysis of variance (ANOVA), followed by Tukey test was used. The analysis of variance revealed a significant difference between the groups. A significant degradation of polymyxin B1 and B2 was observed after 48 hours, a reduction that continued up to the 72 hours of assay. The reduction of polymyxin content was evidenced in both saline and glucose media, at room temperature as well as at $40^{\circ} \mathrm{C}$. Temperature and media (saline solution or glucose solution) did not appear to have a significant influence on the stability of diluted polymyxin B.

The results obtained in this work are similar to those reported by Lim et al. (2016) who determined that polymyxin B was stable in high concentrations in different types of infusion solutions for at least 24 hours at temperatures of 25 and $30^{\circ} \mathrm{C}$. At $4{ }^{\circ} \mathrm{C}$, polymyxin B remained stable for up to 168 hours. It is interesting to 
note that analyses were not performed at $40{ }^{\circ} \mathrm{C}$ as in the present study. The temperature of $40^{\circ} \mathrm{C}$ is suggested for international guidelines to provide information's during accelerated storage conditions (WHO, 2009). If significant changes occur during accelerated stability studies a discussion should be provided to address the effect of it on product storage conditions. In our work polymyxin B was diluted in glucose or saline solutions and the temperature of $40^{\circ} \mathrm{C}$ didn't promoted significant changes in polymyxin $\mathrm{B}$ content when compared with $25^{\circ} \mathrm{C}$.

He et al. 2010 evaluated the stability of polymyxin $\mathrm{B}$ under refrigeration $\left(4^{\circ} \mathrm{C}\right)$ and room temperature $\left(25^{\circ} \mathrm{C}\right)$ by microbiological assay. As in the present work, the authors observed that in the first 24 hours the concentration of polymyxin remained close to $95 \%$ at both temperatures, demonstrating the stability of polymyxin B. In accordance with our work, He et al. (2010) observed that after 48 hours, polymyxin B degraded almost $10 \%$, and after 72 hours its concentration was below $90 \%$. Additionally, the authors reported that at the end of 168 hours, polymyxin B concentrations were $75.4 \%$ at $25^{\circ} \mathrm{C}$ and $78.9 \%$ at $4{ }^{\circ} \mathrm{C}$, respectively.

Physical-chemical instabilities can be evidenced by $\mathrm{pH}$ changes of testing solutions. United States Pharmacopoeia specification for 5\% dextrose injection is pH 3.2-6.5 (USP, 2015). The $\mathrm{pH}$ measured for the $0.9 \%$ sodium chloride injection in our study was within the range of 5.4 to 5.8 , and for glucose solution (5\%) the $\mathrm{pH}$ range was 4.2 to 4.7. No statistical differences were evidenced in these $\mathrm{pH}$ values during $72 \mathrm{hs}$. The results obtained in this work are in agreement with reported by Lim et al. (2016) who evidenced no statistical differences in $\mathrm{pH}$ and osmolarity values of polymyxin B solutions over time.

In previous studies He et al. 2010 evidenced a shorter stability of polymyxin B diluted in $0.9 \%$ sodium chloride solutions, when compared with polymyxin diluted in $0.5 \%$ glucose solutions. The authors observed that the $\mathrm{pH}$ of $0.9 \%$ sodium chloride solutions was less acidic than $5 \%$ dextrose solutions and mentioned that differences in $\mathrm{pH}$ can influence polymyxin B stability, however these results require further investigation, according to the authors.

Orwa et al. (2002) evaluated the stability of polymyxins B1, E1 and E2 in aqueous solutions submitted to different $\mathrm{pH}$ values and temperatures. The authors concluded that polymyxins B1, E1 and E2 are more susceptible to degradation at neutral or basic $\mathrm{pH}$ values.

The stability of polymyxins has also been evaluated in different analytical conditions over the years. Taylor et al. (1994) evaluated the chemical stability of polymyxin $\mathrm{B}$ in aqueous sodium phosphate monobasic buffer at different temperatures $\left(32{ }^{\circ} \mathrm{C}\right.$ to $\left.52{ }^{\circ} \mathrm{C}\right)$ and at different $\mathrm{pH}$ values (2.0 to 10.3 ) over a period of 30 days. The authors showed that a $\mathrm{pH}$ below 7.0 has little effect on the stability of polymyxin $\mathrm{B}$, but $\mathrm{pH}$ values above 7.0 promote drug decomposition reactions.

\section{CONCLUSIONS}

In this work we proposed and validated an analytical method that can be applied to stability studies of polymyxin B. The present work evidenced that polymyxins B1 and B2 diluted in 5\% glucose solution and $0.9 \%$ saline solution remain stable for 24 hours and undergo degradation after this time. Based on the results obtained in this study, it is possible to support the safety of the use of polymyxin $\mathrm{B}$ in saline $(0.9 \%)$ and glucose solutions $(5 \%)$ in an infusion course of 24 hours. No statistical differences were observed in $\mathrm{pH}$ values of glucose solutions and saline solutions containing polymyxin $\mathrm{B}$ and no differences were evidenced, with respect stability of polymyxin $\mathrm{B}$, when it was diluted in saline or glucose solutions at $25^{\circ} \mathrm{C}$ and $40^{\circ} \mathrm{C}$. Considering this, in our analysis conditions, the choice of any of these dissolutions media would be appropriate, considering the polymyxin B stability.

\section{DISCLOSURE OF INTEREST}

The authors report no conflict of interest.

\section{REFERENCES}

He J, Figueroa DA, Lim T-P, Chow DS, Tam VH. Stability of polymyxin B sulfate diluted in $0.9 \%$ sodium chloride injection and stored at 4 or 25 C. Am J Heal Pharm. 2010;67(14):1191-4.

ICH. Harmonised Tripartite Guideline. Stability Testing of New Drug Substances and Products Q1A(R2). 2003.

ICH Harmonised Tripartite Guideline. Validation of Analytical Procedures: Text and Methodology Q2(R1) Guideline on Validation of Analytical Procedures: Methodology developed to complement the Parent Guideline. 2005.

Lim T-P, Hee DK-H, Lee W, Teo JQ-M, Cai Y, Chia SY-H, et al. Physicochemical Stability Study of Polymyxin B in Various Infusion Solutions for Administration to Critically Ill Patients. Ann Pharmacother. 2016;50(9):790-2.

Orwa J, Govaerts C, Gevers K, Roets E, Van Schepdael A, Hoogmartens J. Study of the stability of polymyxins B1, E1 and E2 in aqueous solution using liquid chromatography and mass spectrometry. J Pharm Biomed Anal. 2002;29(1-2):203-12. 
Pogue JM, Ortwine JK, Kaye KS. Clinical considerations for optimal use of the polymyxins: A focus on agent selection and dosing. Clin Microbiol Infect. 2017;23(4):229-33.

Taylor RB, Richards RME, Low AS, Hardie L. Chemical stability of polymyxin B in aqueous solution. Int J Pharm. 1994;102(1-3):201-6.

Thomas TA, Broun EC, Abildskov KM, Kubin CJ, Horan J, Yin MT, et al. High performance liquid chromatographyg-mass spectrometry assay for polymyxin B1 and B2 in human plasma. Ther Drug Monit. 2012;34(4):398-405.

Trissel LA. Handbook of injectable drugs. 17th ed. Bethesda, Maryland: American Society of Health-System Pharmacists; 2012.
United States Pharmacopeial Convention. The United States pharmacopeia : the national formulary. Maryland: Rockville; 2015.

WHO. Stability testing of active pharmaceutical ingredients and finished pharmaceutical products. WHO Tech Rep Ser. 2009;(953):87-130.

Zavascki AP, Goldani LZ, Li J, Nation RL. Polymyxin B for the treatment of multidrug-resistant pathogens: A critical review. J Antimicrob Chemother. 2007;60(6):1206-15.

Received for publication on $09^{\text {th }}$ May 2018 Accepted for publication on $23^{\text {rd }}$ September 2018 